\title{
Epidemiology of chronic obstructive pulmonary disease: a population-based study in Krasnoyarsk region, Russia
}

\author{
Ivan P Artyukhov' \\ Irina L Arshukova ${ }^{2}$ \\ Elena A Dobretsova ${ }^{2}$ \\ Tatyana A Dugina ${ }^{2}$ \\ Andrey $V$ Shulmin ${ }^{2}$ \\ Irina $\vee$ Demko $^{3}$ \\ 'Department of Health Care \\ Management, ${ }^{2}$ Department \\ of Public Health and Health Care, \\ ${ }^{3}$ Department of Internal Diseases, \\ Krasnoyarsk State Medical University, \\ Krasnoyarsk, Russia
}

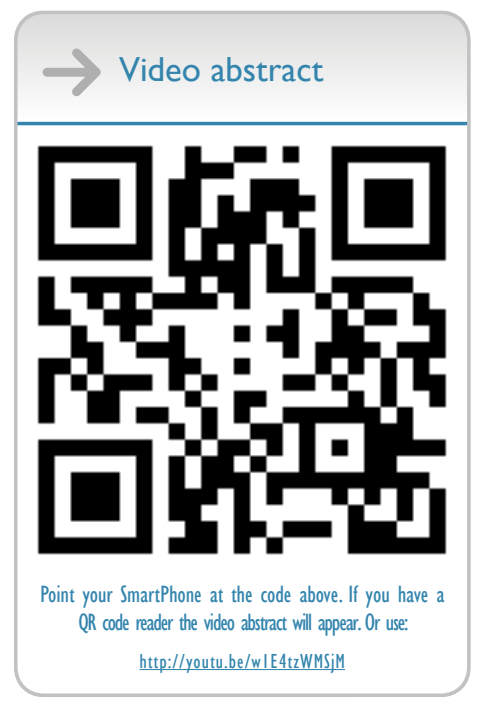

Correspondence: Irina L Arshukova Department of Public Health and Health Care, Krasnoyarsk State Medical University, Partizan Zheleznjak street I, Krasnoyarsk 660022, Russia

Tel +79039200082

Email iarshukova@gmail.com
This article was published in the following Dove Press journal:

International Journal of COPD

2 September 2015

Number of times this article has been viewed

Background: Krasnoyarsk region is a territory with the widespread risk factors for chronic obstructive pulmonary disease (COPD) such as tobacco smoke, air pollution, and occupational exposure. An assessment of COPD prevalence based on medical diagnosis statistics underestimates the true COPD prevalence. This study aims to evaluate how medical examinations may increase the accuracy of estimates of COPD prevalence.

Methods: True COPD prevalence was estimated as a number of patients with the established disease diagnosis supplemented by the additional disease cases detected during medical examinations per 1,000 inhabitants of the region. Official medical statistics data and the data collected from the Global Alliance against Chronic Respiratory Diseases program 2011 among 15,000 inhabitants of the region aged 18 years and older were analyzed.

Results: This study revealed the COPD cases without official medical diagnosis. The true prevalence of COPD is estimated to be two times higher than the prevalence estimates based on medical diagnosis statistics.

Conclusion: Undiagnosed and untreated cases of COPD result in severe COPD forms as well as addition of severe comorbidities. Because of this, there is an increase in the index of potential years of life lost. Conducting special medical examinations may increase the number of COPD cases detected at the early stages of the disease. This, in turn, may reduce the overall burden of the disease for the population of the region.

Keywords: chronic obstructive pulmonary disease, COPD, prevalence, epidemiology

\section{Introduction}

Chronic obstructive pulmonary disease (COPD) is one of the leading causes of morbidity and mortality worldwide, especially in the industrialized and the developing countries. ${ }^{1-6}$ COPD is a progressive pulmonary disease that may have a profound impact on the general health status and quality of life..$^{7-9}$ These factors motivate extensive research studies in this disease area.

Risk factors of COPD development may be divided into two categories: exogenous (tobacco smoke, air pollution, occupational exposure, etc) and endogenous (age, sex, genetic factors, etc). ${ }^{1,10-27}$ Such factors, separately or in synergy, determine the subject's susceptibility level for the disease. ${ }^{1}$ A leading cause for high COPD morbidity rate is delayed diagnosis of the disease. ${ }^{28,29}$ COPD is often detected only after appearance of serious symptoms. Most patients with the initial stages of COPD do not receive much medical attention, in particular with regard to early medical intervention. ${ }^{6}$

Therefore, COPD prevalence estimates based on medical diagnosis statistics do not correspond to the true prevalence of this disease. The goal of our study was to investigate the discrepancy in the COPD prevalence estimates for the Krasnoyarsk region, Russia. 
The reported prevalence of COPD ranged from $0.2 \%$ in Japan to $37 \%$ in the USA, but this varied widely across countries and populations both by the diagnosis method and by the age group analyzed. ${ }^{30}$ Moreover, the assessment of prevalence rates may change considerably according to the diagnostic tools used. ${ }^{1}$ In the Po Delta Valley study, Viegi et al assessed the influence of different spirometric COPD definitions on prevalence estimates. ${ }^{31}$ To define COPD, Global Initiative for Chronic Obstructive Lung Disease (GOLD) criteria are used in a large number of studies. ${ }^{31-34}$ Prevalence of COPD varies significantly in different geographic areas. ${ }^{20}$ The overall COPD prevalence among US adults aged $40-79$ years varied from $10.2 \%$ to $20.9 \%$ based on whether pre- or post-bronchodilator values were used and which diagnostic criterion was applied..$^{35}$ The overall prevalence of COPD in the Netherlands is 3.0\%. ${ }^{3}$ In Denmark, the overall prevalence of COPD is $17.4 \%{ }^{27}$ In Spain, the COPD prevalence is $7.3 \%$ as found by Cabrera López et al and $10 \%$ as found by Gómez Sáenz et al. ${ }^{20,29}$ COPD prevalence among adults aged 40-80 years in Abu Dhabi was reported at $3.7 \% .{ }^{36}$ According to Tageldin et al COPD prevalence in the Middle East and North Africa is 3.6\% ${ }^{37}$ The pooled COPD prevalence defined by GOLD criteria at Latin America and the Caribbean is $13.4 \% .{ }^{33}$ The Italian research based on national medical records reported COPD prevalence at $2.8 \%{ }^{38}$ Assessment of COPD prevalence based on medical diagnosis statistics has been previously reported to underestimate the true COPD prevalence. According to a study from Canada, prevalence of measured airflow obstruction compatible with COPD was two to six times greater (under seven definitions, including the GOLD criteria) than estimates based on self-reports of COPD diagnosis. ${ }^{34}$ Similarly, in a study from Spain, $71.6 \%$ of the subjects were underdiagnosed and $63.5 \%$ undertreated,${ }^{20}$ and another study from Spain reported that over $75 \%$ of cases are still underdiagnosed. ${ }^{29}$ The overall COPD prevalence among Swedish adults aged 40 years and above was reported at $16.2 \%$, and only $29 \%$ of subjects with COPD had a previously diagnosed lung disorder. ${ }^{17}$ The COPD prevalence in Jordan was reported at $12.5 \%$, and only $1.5 \%$ of subjects previously knew about this diagnosis..$^{39}$ In Tunisia, the COPD prevalence was reported at $7.8 \%$, while only $3.5 \%$ of participants reported medically diagnosed COPD. ${ }^{14}$ COPD continues to be an understudied, underdiagnosed, and undertreated disorder, especially in the developing world. ${ }^{17,33}$ In Russia, as elsewhere in the developing world, available data on the epidemiology of COPD are limited.

The purpose of this study was to investigate a true prevalence of COPD in Krasnoyarsk region, Russia. Krasnoyarsk region is one of the major counties of the Russian
Federation with a population of approximately three million people covering the territory, equal to about $14 \%$ of the entire country. Krasnoyarsk region is one of the ten donor-regions, forming more than $50 \%$ of the gross domestic product of the Russian Federation and the federal budget. It is the absolute leader among the regions of the country in the development of industrial product per capita. Industrial enterprises (such as chemical and metallurgical industries), located in the regional territory, are harmful to public health. In the Krasnoyarsk, about $46 \%$ of the adult populations are active smokers: $65 \%$ men and 30\% women. ${ }^{40}$ The prevalence of smoking in the Krasnoyarsk region is higher than anywhere else in Russia. According to the Global Adult Tobacco Survey 2009, 39.1\% of the adult population of Russia are regular smokers: $60.2 \%$ men and $21.7 \%$ women. ${ }^{41}$ Krasnoyarsk region is a territory with widespread risk factors for COPD, such as tobacco smoke, air pollution, and work exposure. Therefore, investigation and prevention of COPD is important in Krasnoyarsk region.

\section{Methods}

To estimate a true prevalence of a chronic disease, we have to estimate its point prevalence rate. A prevalence rate is the number of patients with the established disease diagnosis supplemented by the additional disease cases detected during medical examinations and the number of cases that caused the patient's death (per 1,000). It is calculated as follows: ${ }^{42}$

$$
P_{\mathrm{r}}=\frac{N_{\mathrm{e}}+N_{\mathrm{d}}+N_{\mathrm{m}}}{N} \times 1,000
$$

where $P_{\mathrm{r}}$ is the true prevalence of the disease (per 1,000), $N_{\mathrm{e}}$ the number of patients with the established disease diagnosis, $N_{\mathrm{d}}$ the number of disease cases detected during medical examinations, $N_{\mathrm{m}}$ the number of disease cases that caused the patient's death, and $N$ the average annual population. All these numbers are taken for a particular year.

It should be noted that in the Russian Federation COPD is rarely officially diagnosed as the cause of the patient's death: it is estimated that $N_{\mathrm{m}}$ is approximately equal to $1 \%$ of a true prevalence $P_{\mathrm{r}}{ }^{42}$ Patients with COPD have a higher level of comorbidities than the general population. ${ }^{29}$ Usually, these comorbidities are assumed as the causes of the patient's death. As it was shown by Afonso et al mortality rates differ substantially between COPD patients and non-COPD subjects of the same age, underlining the burden of this disease. ${ }^{3}$ Thus, the component $N_{\mathrm{m}}$ is negligibly small and can be overlooked in our estimations.

The average annual population $N$ can be obtained from the official statistics of the Krasnoyarsk region. The number 
of patients with an established COPD diagnosis $N_{\mathrm{e}}$ can be obtained from the databases of territorial body of state statistics of Krasnoyarsk region. These databases contain information about the medically reported presence of any chronic disease for all the patients in the region.

Identification of patients (residents of the Krasnoyarsk region) with unestablished diagnosis of COPD $\left(N_{\mathrm{d}}\right.$ value) was carried out using data collected from the Global Alliance against Chronic Respiratory Diseases (GARD) program 2011.43 This study covered 15,000 inhabitants of the Krasnoyarsk region aged 18 years and older. In this program, subjects were selected among the inhabitants of the region using cluster geographical randomization to control for age-sex composition of subject cohorts and differences in population size of the various districts in the Krasnoyarsk region. Participants completed a questionnaire and then performed spirometry with bronchodilator testing if obstruction was observed. COPD was diagnosed according to the GOLD criteria guidelines: the presence of a post-bronchodilator forced expiratory volume in one second $\left(\mathrm{FEV}_{1}\right)$ less than $80 \%$ of the predicted value in combination with a $\mathrm{FEV}_{1} /$ forced vital capacity (FVC) less than $70 \%$ confirms the diagnosis of COPD. ${ }^{32}$

\section{Ethical approval}

No ethical approval was sought for this paper. In this work the databases of the Territorial body of state statistics of Krasnoyarsk region and the data collected from the Global Alliance against Chronic Respiratory Diseases (GARD) program 2011 were used as the information sources. These databases are depersonalized and provide only statistical information.

\section{Results COPD prevalence based on medical diagnosis statistics}

The number of adult patients (18 years and older) with the medically established COPD diagnosis in the Krasnoyarsk region in 2011 was 23,244 ( $N_{\mathrm{e}}$ value) according to the databases of territorial body of state statistics of Krasnoyarsk region. The average annual population of the region (18 years and older) was $2,193,962$. Thus, the official COPD prevalence is 10.6 per 1,000 inhabitants of the region (18 years and older).

\section{Additionally diagnosed cases of COPD and the true COPD prevalence}

The GARD study revealed 159 patients with previously undiagnosed COPD among 15,000 of the participants. This corresponds to 23,256 additional cases of COPD ( $N_{\mathrm{d}}$ value) among the adult inhabitants of the Krasnoyarsk region. Thus, the true COPD prevalence among the adult population of the Krasnoyarsk region is (per 1,000):

$$
P_{\mathrm{r}}=\frac{23,244+23,256}{2,193,962} \times 1,000 \approx 21.2
$$

This prevalence is two times higher than the COPD prevalence based only on medical diagnosis statistics.

\section{Age distribution of the patients with an established COPD diagnosis and the additional disease cases detected during medical examinations}

Distribution of patients with an established COPD diagnosis and the additional disease cases by age groups are shown in Table 1 for men and Table 2 for women (per 100,000 inhabitants of the region).

In Figure 1, we demonstrate the distribution of the number of patients with an established COPD diagnosis and the additional disease cases per 100,000 by age group: Figure 1A, distribution for men and Figure 1B, distribution for women. The total number of men with COPD is higher than the total number of women with COPD for both established and additionally diagnosed cases of COPD due to the fact that harmful factors affect more men than women (smoking, occupational exposure, etc). From this figure, we can conclude that the true

Table I Distribution of patients with an established COPD diagnosis and the additional disease cases by the age groups for men, Krasnoyarsk region, $201 \mathrm{I}$

\begin{tabular}{|c|c|c|c|c|c|}
\hline $\begin{array}{l}\text { Age } \\
\text { group, } \\
\text { years }\end{array}$ & $\begin{array}{l}\text { Patients with } \\
\text { an established COPD } \\
\text { diagnosis (per } 100,000 \text { ) }\end{array}$ & $\begin{array}{l}\text { Additionally } \\
\text { diagnosed cases } \\
\text { of COPD (per I00,000) }\end{array}$ & $\begin{array}{l}\text { True COPD } \\
\text { prevalence } \\
\text { (per } 100,000)\end{array}$ & $\begin{array}{l}\text { Percentage ratio } \\
\text { of established } \\
\text { COPD diagnosis }\end{array}$ & $\begin{array}{l}\text { Percentage ratio } \\
\text { of additionally diagnosed } \\
\text { COPD cases }\end{array}$ \\
\hline $18-30$ & 0 & 47 & 47 & 0 & 100 \\
\hline $31-40$ & 0 & 53 & 53 & 0 & 100 \\
\hline $4 I-50$ & 35 & 87 & 122 & 28.7 & 71.3 \\
\hline $51-60$ & 202 & 220 & 422 & 47.9 & 52.1 \\
\hline $6 I-70$ & 214 & 253 & 467 & 45.8 & 54.2 \\
\hline$>70$ & 114 & 113 & 227 & 50.2 & 49.8 \\
\hline
\end{tabular}


Table 2 Distribution of patients with an established COPD diagnosis and the additional disease cases by the age groups for women, Krasnoyarsk region, 20II

\begin{tabular}{llllll}
\hline $\begin{array}{l}\text { Age } \\
\text { group, } \\
\text { years }\end{array}$ & $\begin{array}{l}\text { Patients with } \\
\text { an established COPD } \\
\text { diagnosis (per 100,000) }\end{array}$ & $\begin{array}{l}\text { Additionally } \\
\text { diagnosed cases } \\
\text { of COPD (per 100,000) }\end{array}$ & $\begin{array}{l}\text { True COPD } \\
\text { prevalence } \\
\text { (per 100,000) }\end{array}$ & $\begin{array}{l}\text { Percentage ratio } \\
\text { of established } \\
\text { COPD diagnosis }\end{array}$ & $\begin{array}{l}\text { Percentage ratio } \\
\text { of additionally diagnosed } \\
\text { COPD cases }\end{array}$ \\
\hline $18-30$ & 0 & 0 & 0 & - & - \\
$31-40$ & 0 & 67 & 67 & 0 & 100 \\
$41-50$ & 13 & 73 & 86 & 15.1 & 84.9 \\
$51-60$ & 75 & 101 & 176 & 42.6 & 57.4 \\
$61-70$ & 79 & 32 & 111 & 71.2 & 28.8 \\
$>70$ & 42 & 13 & 55 & 76.4 & 23.6 \\
\hline
\end{tabular}

prevalence of COPD is maximal in the 61-70 age group for men and in the 51-60 age group for women. There are no established COPD diagnosis cases for the age groups 18-30 and 31-40 for both men and women. This may occur due to the fact that clinical symptoms of COPD are not yet present in these age groups. Identification of patients (residents of the Krasnoyarsk region) with unestablished COPD diagnosis is the main contributor to the cases of COPD in the age groups $18-30$ and $31-40$ for men and the age group 31-40 for women.

In Figure 2, we show the percentage ratio of patients with an established COPD diagnosis and additional disease cases for each age group: Figure 2A, distribution for men and Figure 2B, distribution for women.

It is clear from the figure that the percentage ratio of the established COPD diagnosis is increasing (and the percentage ratio of additionally diagnosed cases of COPD is decreasing) with the increasing age of the patients. This dependence is more strongly pronounced for women than for men.
Therefore, we can conclude that COPD diagnosis is well established in the older age groups when the disease symptoms become clearly expressed. However, in the young age groups, the COPD diagnosis is not established at all (40 years old and less). At this age, clinical symptoms of COPD are usually not expressed enough. Even if some symptoms are present, patients do not pay sufficient attention to them and do not seek medical care. In the young age groups (40 years old and less), COPD diagnosis can be established only by means of a special medical examination. Because COPD can be readily and successfully treated during the early stages of the disease, it is important to recognize and diagnose COPD as early as possible.

Comparison of the data for men and for women reveals that in older ages ( 70 years and more), only $58.0 \%$ of men with COPD have a medically established COPD diagnosis, while among women, this is $81.7 \%$. This difference may be attributed to the fact that women are often more attentive to adverse clinical symptoms than men and are more likely to seek medical attention.

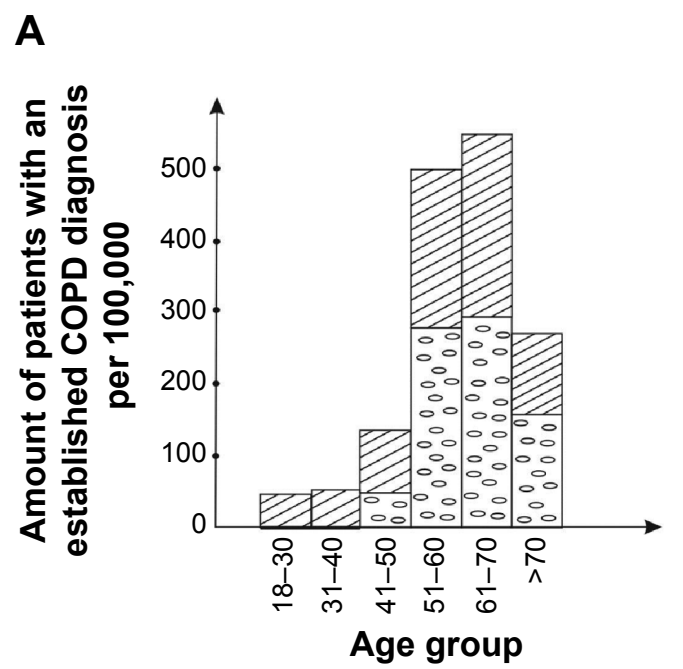

B

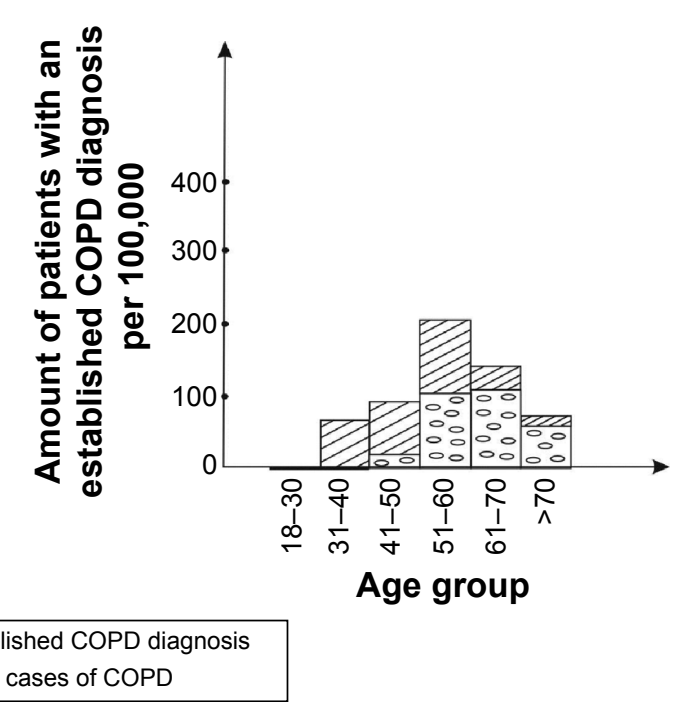

Figure I The distribution of the patients with an established COPD diagnosis and the additional disease cases (per 100,000) by age groups. Notes: (A) For men and (B) for women. 
A

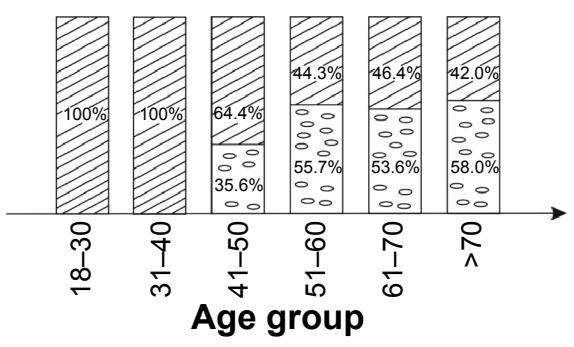

B

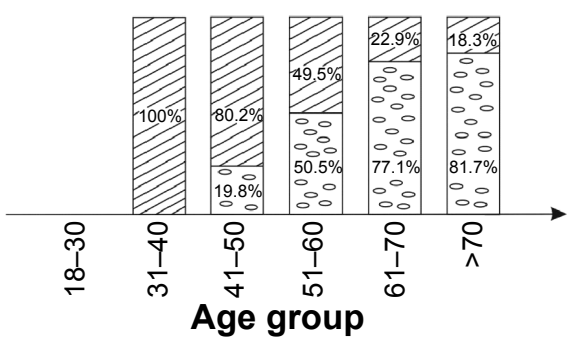

을 Patients with the established COPD diagnosis

$叉$ Additionally diagnosed cases of COPD

Figure 2 The distribution of the percentage ratio for patients with the established COPD diagnosis and the additional disease cases by the age group. Notes: (A) For men and (B) for women.

As demonstrated in Figure 2, there is also a difference in diagnosis between men and women in the 41-50 age group. Only $19.8 \%$ of women with COPD have a medically established COPD diagnosis, while among men, this is $35.6 \%$. This difference may be explained by the fact that symptoms associated with COPD present earlier in men than in women. This may occur because men usually start smoking at earlier ages than women with more intense smoking habits. Men are also more likely to come in contact with occupational exposure than women.

\section{Conclusion}

The prevalence of COPD in Russia is underestimated, as in the case in many other countries. ${ }^{14,17,20,29,33,34,39}$ The aim of this study was to investigate the true prevalence of COPD in one of the largest territories of the Russian Federation - the Krasnoyarsk region.

It was reported that COPD prevalence based on medical diagnosis statistics is 10.6 per 1,000 inhabitants of the region. Identification of patients (residents of the Krasnoyarsk region) with unestablished diagnosis of COPD was conducted within the GARD study 2011. The true prevalence of COPD was estimated to be approximately 21.2 per 1,000 inhabitants of the region. It is two times greater than the estimates based on medical diagnosis statistics. This means that half of the subjects with COPD are not diagnosed, and therefore, are not receiving appropriate treatment for their lung disease.

The COPD diagnosis is established only in the older age groups, while in the young age groups (40 years old and less), it is not established at all. At this age, patients do not pay sufficient attention to the symptoms of COPD and do not seek medical care.

Late identification of COPD results in severe forms of COPD as well as addition of severe comorbidities. Because of this, the index of potential years of life lost and the overall burden of the disease for the population of the region are growing. To address this, it is necessary to carry out special medical examinations to increase the fraction of medically reported cases of COPD. Recognition of COPD at the early stages of the disease can lead to increased success in COPD treatment and a reduction in the overall burden of the disease for the population of the region.

\section{Disclosure}

The authors report no conflicts of interest in this work.

\section{References}

1. Viegi G, Maio S, Pistelli F, Baldacci S, Carrozzi L. Epidemiology of chronic obstructive pulmonary disease: health effects of air pollution. Respirology. 2006;11:523-532.

2. Viegi G, Scognamiglio A, Baldacci S, Pistelli F, Carrozzi L. Epidemiology of chronic obstructive pulmonary disease: health effects of air pollution (COPD). Respirology. 2001;68:4-19.

3. Afonso AS, Verhamme KM, Sturkenboom MC, Brusselle GG. COPD in the general population: prevalence, incidence and survival. Respir Med. 2011;105:1872-1884.

4. Lopez AD, Mathers CD, Ezzati M, Jamison DT, Murray CJ, editors. Global Burden of Disease and Risk Factors. Washington: World Bank; 2006.

5. Lopez AD, Shibuya K, Rao C, et al. Chronic obstructive pulmonary disease: current burden and future projections. Eur Respir J. 2006; 27(2):397-412.

6. Li X, Zhou Y, Chen S, Zheng J, Zhong N, Ran P. Early intervention with tiotropium in Chinese patients with GOLD stages I-II chronic obstructive pulmonary disease (Tie-COPD): study protocol for a multicentre, doubleblinded, randomised, controlled trial. BMJ Open. 2014;4(2):e003991.

7. Polatli M, Ben Kheder A, Wali S, et al; for BREATHE Study Group. Chronic obstructive pulmonary disease and associated healthcare resource consumption in the Middle East and North Africa: the BREATHE study. Respir Med. 2012;106(suppl 2):S75-S85.

8. Uzaslan E, Mahboub B, Beji M, et al; for BREATHE Study Group. The burden of chronic obstructive pulmonary disease in the Middle East and North Africa: results of the BREATHE study. Respir Med. 2012; 106(suppl 2):S45-S59.

9. Idrees M, Koniski ML, Taright S, et al; for BREATHE Study Group. Management of chronic obstructive pulmonary disease in the Middle East and North Africa: results of the BREATHE study. Respir Med. 2012;106(suppl 2):S33-S44. 
10. Lindberg A, Jonsson AC, Rönmark E, Lundgren R, Larsson LG, Lundbäck B. Ten-year cumulative incidence of COPD and risk factors for incident disease in a symptomatic cohort. Chest. 2005;127(5): 1544-1552.

11. Hagstad S, Bjerg A, Ekerljung L, et al. Passive smoking exposure is associated with increased risk of COPD in never smokers. Chest. 2014; 145(6):1298-1304.

12. Sanjuán P, Golpe R, Pérez-de-Llano L, Cano E, Castro-Añon O. Clinical differences between patients with COPD due to biomass smoke or tobacco. Chest. 2014;145(suppl 3):421A.

13. Zhou Y, Chen R. Risk factors and intervention for chronic obstructive pulmonary disease in China. Respirology. 2013;18(suppl 3):4-9.

14. Daldoul H, Denguezli M, Jithoo A, et al. Prevalence of COPD and tobacco smoking in Tunisia - results from the BOLD study. Int J Environ Res Public Health. 2013;10(12):7257-7271.

15. Sexton $P, B$ lack $P, W u L$, et al. Chronic obstructive pulmonary disease in non-smokers: a case-comparison study. COPD. 2014;11(1):2-9.

16. Buist AS, McBurnie MA, Vollmer WM, et al; for BOLD Collaborative Research Group. International variation in the prevalence of COPD (the BOLD Study): a population-based prevalence study. Lancet. 2007;370(9589):741-750.

17. Danielsson P, Ólafsdóttir IS, Benediktsdóttir B, Gíslason T, Janson C. The prevalence of chronic obstructive pulmonary disease in Uppsala, Sweden - the Burden of Obstructive Lung Disease (BOLD) study: crosssectional population-based study. Clin Respir J. 2012;6(2):120-127.

18. Hill K, Goldstein RS, Guyatt GH, et al. Prevalence and underdiagnosis of chronic obstructive pulmonary disease among patients at risk in primary care. CMAJ. 2010;182(7):673-678.

19. Diaz-Guzman E, Mannino DM. Epidemiology and prevalence of chronic obstructive pulmonary disease. Clin Chest Med. 2014;35(1):7-16.

20. Cabrera López C, Juliá Serdá G, Cabrera Lacalzada C, et al. Prevalencia de enfermedad pulmonar obstructiva crónica en las Islas Canarias [Prevalence of chronic obstructive pulmonary disease in the Canary Islands]. Arch Bronconeumol. 2014;50(7):272-277.

21. Pallasaho P, Kainu A, Sovijärvi A, Lindqvist A, Piirilä PL. Combined effect of smoking and occupational exposure to dusts, gases or fumes on the incidence of COPD [abstract]. COPD. 2014;11(1):88-95.

22. Hasnaoui EA, Rashid N, Lahlou A, et al; for BREATHE Study Group. Chronic obstructive pulmonary disease in the adult population within the Middle East and North Africa region: rationale and design of the BREATHE study. Respir Med. 2012;106(suppl 2):S3-S15.

23. Rumana HS, Sharma RC, Beniwal V, Sharma AK. A retrospective approach to assess human health risks associated with growing air pollution in urbanized area of Thar Desert, western Rajasthan, India. J Environ Health Sci Eng. 2014;12(1):23.

24. Schikowski T, Adam M, Marcon A, et al. Association of ambient air pollution with the prevalence and incidence of COPD. Eur Respir J. 2014; 44(3):614-626.

25. Schikowski T, Mills IC, Anderson HR, et al. Ambient air pollution: a cause of COPD? Eur Respir J. 2014;43(1):250-263.

26. Chhabra SK, Chhabra P. Estimating prevalence of chronic obstructive pulmonary disease: from questionnaires to spirometry. Indian J Chest Dis Allied Sci. 2012;54(3):155-158.

27. Fabricius P, Løkke A, Marott JL, Vestbo J, Lange P. Prevalence of COPD in Copenhagen. Respir Med. 2011;105:410-417.
28. Kart L, Akkoyunlu ME, Bayram M, et al. COPD: eine unterdiagnostizierte Erkrankung. Ergebnisse einer Screeningstudie in der Umgebung eines Spitals [COPD: an underdiagnosed disease at hospital environment]. Wien Klin Wochenschr. 2014;126(3-4):73-78. [German].

29. Gómez Sáenz JT, Quintano Jiménez JA, Hidalgo Requena A, et al. Enfermedad pulmonar obstructiva crónica: morbimortalidad e impacto sanitario [Chronic obstructive pulmonary disease: morbimortality and healthcare burden]. Semergen. 2014;40(4):198-204. [Spanish].

30. Rycroft CE, Heyes A, Lanza L, Becker K. Epidemiology of chronic obstructive pulmonary disease: a literature review. Int J Chron Obstruct Pulmon Dis. 2012;7:457-494.

31. Viegi G, Pedreschi M, Pistelli F, et al. Prevalence of airways obstruction in a general population: European Respiratory Society vs American Thoracic Society definition. Chest. 2000;117(5 suppl 2):339S-345S.

32. GOLD. Global Strategy for the Diagnosis, Management, and Prevention of Chronic Obstructive Pulmonary Disease. Global Initiative for Chronic Obstructive Lung Disease (GOLD); 2014.

33. Ciapponi A, Alison L, Agustina M, Demián G, Silvana C, Edgardo S. The epidemiology and burden of COPD in Latin America and the Caribbean: systematic review and meta-analysis. COPD. 2014;11(3): 339-350.

34. Evans J, Chen Y, Camp PG, Bowie DM, McRae L. Estimating the prevalence of COPD in Canada: reported diagnosis versus measured airflow obstruction. Health Rep. 2014;25(3):3-11.

35. Tilert T, Dillon C, Paulose-Ram R, Hnizdo E, Doney B. Estimating the U.S. prevalence of chronic obstructive pulmonary disease using pre- and post-bronchodilator spirometry: the National Health and Nutrition Examination Survey (NHANES) 2007-2010. Respir Res. 2013;14:103.

36. Al Zaabi A, Asad F, Abdou J, et al. Prevalence of COPD in Abu Dhabi, United Arab Emirates. Respir Med. 2011;105(4):566-570.

37. Tageldin MA, Nafti S, Khan JA, et al; for BREATHE Study Group. Distribution of COPD-related symptoms in the Middle East and North Africa: results of the BREATHE study. Respir Med. 2012;106(supp1 2): S25-S32.

38. Cazzola M, Puxeddu E, Bettoncelli G, et al. The prevalence of asthma and COPD in Italy: a practice-based study. Respir Med. 2011;105(3): 386-391.

39. Khassawneh B, Al-Omari M, Khader Y, Dauod AS, Amarin Z, Bergus G. Prevalence of chronic obstructive pulmonary disease among adult male smokers in Jordan. Chest. 2014;145(suppl 3):365A.

40. Aristov AI, Demko IV, Kononova LI, et al. Okazanie meditsinskoy pomoshchi $v$ otkaze ot kureniya tabaka [Medical Assistance in Tobacco Smoking Cessation]. Vol. 34. Krasnoyarsk: KrasGMU; 2011. [Russian].

41. World Health Organization. Global Adult Tobacco Survey (GATS) Russian Federation 2009 Country Report. Geneva, Switzerland: World Health Organization; 2010. Available from: http://www.who.int/entity/ tobacco/surveillance/en_tfi_gats_russian_countryreport.pdf. Accessed November 11, 2014.

42. Lisitsyn YP, Ulumbekova GY. Obshchestvennoe zdorov'e i zdravookhranenie [Public Health and Health Service]. Moscow: GEOTARMedia; 2011:544. [Russian].

43. Chuchalin AG, Khaltaev N, Antonov NS, et al. Chronic respiratory diseases and risk factors in 12 regions of Russian Federation. Int J Chron Obstruct Pulmon Dis. 2014;9:963-974.
International Journal of COPD

\section{Publish your work in this journal}

The International Journal of COPD is an international, peer-reviewed journal of therapeutics and pharmacology focusing on concise rapid reporting of clinical studies and reviews in COPD. Special focus is given to the pathophysiological processes underlying the disease, intervention programs, patient focused education, and self management protocols.

\section{Dovepress}

This journal is indexed on PubMed Central, MedLine and CAS. The manuscript management system is completely online and includes a very quick and fair peer-review system, which is all easy to use. Visit http://www.dovepress.com/testimonials.php to read real quotes from published authors. 